\title{
Determinants of multiple psychotropic drug use in patients with mild intellectual disabilities or borderline intellectual functioning and psychiatric or behavioral disorders
}

\author{
Joost J. Stolker, M.D. ${ }^{\mathrm{a}, \mathrm{b}}, *$, Eibert R. Heerdink, Ph.D. ${ }^{\mathrm{b}}$, Hubert G.M. Leufkens, Ph.D. ${ }^{\mathrm{b}}$, \\ Mariet G.M. Clerkx, M.D. ${ }^{a}$, Willem A. Nolen, M.D., Ph.D. ${ }^{\mathrm{a}, \mathrm{c}}$ \\ ${ }^{a}$ Altrecht, Institute for Mental Health Care, Den Dolder, The Netherlands \\ ${ }^{\mathrm{b}}$ Department of Pharmacoepidemiology and Pharmacotherapy, Utrecht Institute for Pharmaceutical Sciences (UIPS), Utrecht, The Netherlands \\ ${ }^{\mathrm{c}}$ Department of Psychiatry, University Medical Center Utrecht, Utrecht, The Netherlands
}

\begin{abstract}
Prevalence rates of psychotropic drug use in people with intellectual disabilities are high and pharmacotherapy is often attempted with multiple drugs. The presence of disruptive behavior is an important factor associated with the use of psychotropic drugs in this population. We wanted to gain insight into prevalence and determinants of multiple psychotropic drug use among patients with mild intellectual disabilities or borderline intellectual functioning with psychiatric or behavioral disorders. Therefore, data on psychotropics and possible determinants of use were retrospectively collected during 1992-1997 in a specialized closed ward of a Dutch general psychiatric hospital. We defined multiple drug use as concomitant prescription (regular or as needed) of a combination of benzodiazepines/tranquilizers/ antipsychotics/anticonvulsants/anti-depressants. Multiple drug use, seen in $48 \%$ of the patients, was associated with a long duration of stay, psychosis, aggressive, bizarre, attention-seeking behavior and involuntary measures. We conclude that it is likely that difficulties in the management of socially disruptive behavior are often countered by multiple drug prescription. (C) 2001 Elsevier Science Inc. All rights reserved.
\end{abstract}

Keywords: Polypharmacy; Psychotropic drugs; Intellectual Disability; Hospitals; Psychiatric; Mental disorders

\section{Introduction}

Studies on the prevalence of mental disorders in people with intellectual disabilities have shown higher rates than those found in the general population [1-5]. Recurrent crises because of aggressive and other disruptive behaviors are strongly associated with psychotropic drug use [6] and pharmacotherapy is often attempted with multiple drugs in this population [7]. In two recent surveys, the prevalence of the use of more than one psychotropic drug ranged from 10,7\% of 1,101 residents of over 120 group homes in the U.S. to about a quarter of 520 adults living in institutions or community based settings in the U.K. [8,9]. Multiple drug use may be in some cases appropriate but can also be reason for concern in other cases because the more drugs a patient uses the greater the risk on frequent and serious untoward inter-

\footnotetext{
* Corresponding author. Tel.: +31-30-2256306; fax: +31-302256967.

E-mail address: j.stolker@altrecht.nl (J. Stolker).
}

actions and side-effects which can interfere with cognitive and behavior skills $[10,11]$.

We performed a retrospective study into the prevalence of multiple psychotropic drug use in patients with mild intellectual disabilities or borderline intellectual functioning and psychiatric or behavioral disorders admitted to a specialized closed ward of a psychiatric hospital. Furthermore we wanted to gain insight into multiple drugs by analyzing possible determinants of use.

\section{Materials and methods}

\subsection{Patients and data collection}

Data were retrospectively collected over the years 1992 1997 from a consecutive sample of 105 patients of 16 years or older concerning their first admission to a specialized closed ward for people with mild intellectual disabilities or borderline intellectual functioning and psychiatric or behav- 
ioral disorders. Patient data (gender, age, level of intellectual functioning, psychiatric diagnosis, behavioral diagnosis, application of involuntary measures, duration of stay) and data on the use of psychotropics (type of medication, -benzodiazepines, tranquilizers including droperidol, levomepromazine and promethazine, antipsychotics, anticholinergics, anticonvulsants, antidepressants and lithium-, dosage, duration of treatment) were extracted from the medical records by means of a standardized data collection form. The study protocol was approved by the Ethics Committee of the University Medical Center Utrecht.

\subsection{The ward}

The closed ward is part of a general psychiatric hospital and has 24 beds. It serves an area of four million people coming from the west and middle regions of the Netherlands. Almost all patients have long histories of recurrent admissions to psychiatric hospitals or to specialized units of residential settings. The primary purpose of the ward is to establish a psychiatric- or behavioral diagnosis and improve the behavior by prolonged treatment and rehabilitation.

\subsection{Psychiatric and behavioral diagnosis}

Psychiatric diagnoses according to DSM-III-R/-IV criteria were made during the first month of hospitalization by the psychiatrist (MGMC) of the unit. Additionally, reasons for admission were classified into six categories of behavioral diagnoses: antisocial, aggressive (including self mutilation and suicidal behavior), withdrawal, sexually unacceptable, bizarre, and attention seeking behavior.

As a proxy for destructive behavior during hospitalization we used the number of days on which involuntary measures, mostly seclusion, were taken.

\subsection{Use of psychotropic medication}

Multiple drug use was defined as concomitant prescription (regular or as needed) of: 1) two antipsychotics; 2) antipsychotic and anticonvulsant; 3) antidepressant and anticonvulsant; 4) antidepressant and antipsychotic; 5) tranquilizer and benzodiazepine and antipsychotic; 6) tranquilizer and benzodiazepine and anticonvulsant; and 7) tranquilizer and benzodiazepine and antidepressant. Combinations with anticonvulsants were taken into account because these agents are often prescribed for psychiatric or behavioral disorders in this population. Combinations with anticholinergics were not taken into account because the addition of these agents to antipsychotic agents is common because of extrapyramidal side effects.

During the first month of hospitalization patients are usually observed for diagnostic purposes and new treatments based on the results of these observations start after this period. Medication used during the first month was often a continuation of the medication prescribed by the referring physician. Therefore we defined psychotropic drugs during hospitalization by excluding drugs only used during this month.

Medication was coded according to the WHO Anatomical Therapeutic Chemical (ATC) coding system. Daily exposure to psychotropics was standardized in number of Defined Daily Doses (DDD-equivalents), a standardized technical unit of measurement defined as the average dose per day for a drug used for its main indication in adults [12]. As needed medication was also included in the analysis.

\subsection{Analysis}

In a nested case-control analysis we compared patients exposed to multiple drugs with patients not exposed to multiple drugs and calculated odds ratios for various possible determinants including gender, age, level of intellectual functioning, psychiatric diagnosis, behavioral diagnosis, application of involuntary measures and duration of stay. Adjustment for possible confounding was performed by an unconditional logistic regression analysis with multiple drug status as the dependent variable and possible determinants as independent variables. All analyses were performed with SPSS package and EGRET.

\section{Results}

The study population consisted of 96 patients with a duration of stay of more than one month. Nine patients with a hospitalization shorter than 1 month were excluded. The patients were predominantly young with a mean age of 26.6 years ranging from 16 to 57 years and a median of 24 years. Male patients $(71.9 \%)$ outnumbered female patients. Patients with borderline intellectual functioning comprised $45.8 \%$, patients with mild intellectual disabilities $49.0 \%$ and patients with moderate intellectual disabilities $5.2 \%$ of the population. Of 76 patients data on discharge were available. The remaining 20 were still hospitalized at the end of the follow-up. The mean length of stay of all 76 patients with completed hospitalizations at the end of the study was 388.3 days ranging from 38 to 1,734 days with a median of 270.5 days. Patients using regular or as needed psychotropic drugs during hospitalization had an average length of stay of 435.5 days ranging from 38 to 1,734 days with a median of 295 days whereas the average length of stay for patients using no psychotropic drugs was 196.6 days, ranging form 47 to 538 days with a median of 128 days.

Table 1 shows data on the regular use of psychotropic agents. At admission and discharge point prevalence rates were calculated. During stay the period prevalence was estimated. At admission $63.5 \%$ of the patients used psychotropic drugs including anticonvulsants, during stay $79.2 \%$ and at discharge $69.7 \%$. Antipsychotics and benzodiazepines were most frequently used. Pipamperone was the most commonly prescribed antipsychotic and was used by 
Table 1

Prevalence of regular psychotropic drug use at the first day of stay (referral medication), during stay and at the day of discharge. At admission and discharge point prevalence rates were calculated and during stay the period prevalence was estimated. For 76 of 96 patients, data on discharge were available.

\begin{tabular}{|c|c|c|c|c|c|c|}
\hline & \multicolumn{2}{|c|}{ Referral medication $(\mathrm{n}=96) \mathrm{n}(\%)$} & \multicolumn{2}{|c|}{ Medication during stay $(\mathrm{n}=96) \mathrm{n}(\%)$} & \multicolumn{2}{|c|}{ Medication at discharge $(\mathrm{n}=76) \mathrm{n}(\%)$} \\
\hline & Number of patients & Average daily dose & Number of patients & Average daily dose & Number of patients & Average daily dose \\
\hline Antipsychotics & $49(51.0)$ & 1.3 & $64(66.7)$ & 1.1 & $42(55.3)$ & 1.4 \\
\hline Benzodiazepines & $30(31.3)$ & 1.5 & $53(55.2)$ & 1.4 & $33(43.4)$ & 1.2 \\
\hline Tranquilizers & $11(11.5)$ & 1.3 & $20(20.8)$ & 2.2 & $10(13.2)$ & 2.2 \\
\hline Antidepressants & $13(13.5)$ & 1.2 & $25(26.0)$ & 1.1 & $6(7.9)$ & 0.8 \\
\hline Lithium & $1(1.0)$ & $*$ & $4(4.2)$ & $*$ & $2(2.6)$ & $*$ \\
\hline Anticonvulsants & $12(12.5)$ & 1.8 & $18(18.8)$ & 1.4 & $10(13.2)$ & 1.3 \\
\hline Anticholinergics & $19(19.8)$ & 0.7 & $27(28.1)$ & 0.7 & $12(15.8)$ & 0.8 \\
\hline
\end{tabular}

* Lithium has no DDD.

$19(19.8 \%)$ of all patients and $29.7 \%$ of all antipsychotic consumers during stay. Oxazepam was the most frequently prescribed benzodiazepine, used by $32(33.3 \%)$ of all patients and $60.4 \%$ of benzodiazepine users. Antipsychotics were prescribed in the widest dose range from 0.1 (thioridazine) to 2.7 DDD-equivalents per day (haloperidol). In 46 patients $(47.9 \%)$ multiple drugs were prescribed during stay. Of the multiple drug users, nine used an anticonvulsant from which five had a diagnosis of seizure disorder.
In Table 2 determinants of multiple psychotropic drug use are listed. Psychotic disorder, aggressive behavior and bizarre behavior were significantly associated with multiple psychotropic drug use. Attention seeking behavior was also associated with multiple drug use, although not statistically significant as was the association with duration of stay. Since we were interested in determinants of multiple psychotropic drug use we looked at involuntary measures taken on days before multiple drug prescription. Only patients

Table 2

Patient parameters and multiple psychotropic drug use*-Adjusted odds ratios calculated with $95 \%$ confidence interval (95\% CI). Significant associations are printed in bold.

\begin{tabular}{|c|c|c|c|c|}
\hline & $\begin{array}{l}\text { Multiple drug users } \\
(\mathrm{n}=46) \mathrm{n}(\%)\end{array}$ & $\begin{array}{l}\text { No multiple drug users } \\
(\mathrm{n}=50) \mathrm{n}(\%)\end{array}$ & $\begin{array}{l}\text { Crude Odds Ratio } \\
(95 \% \mathrm{CI})\end{array}$ & $\begin{array}{l}\text { Adjusted Odds Ratio } \\
(95 \% \mathrm{CI})\end{array}$ \\
\hline Male & $31(67.4)$ & $38(76.0)$ & 1.0 (reference) & 1.0 (reference) \\
\hline Female & $15(32.6)$ & $12(24.0)$ & $1.5(0.6-3.8)$ & $1.8(0.5-6.8)$ \\
\hline \multicolumn{5}{|l|}{ Age (years) } \\
\hline $16-20$ & $10(21.7)$ & $11(22.0)$ & 1.0 (reference) & 1.0 (reference) \\
\hline $20-30$ & $22(47.8)$ & $23(46.0)$ & $1.1(0.4-3.0)$ & $0.9(0.2-3.6)$ \\
\hline$\geq 30$ & $14(30.4)$ & $16(32.0)$ & $1.0(0.3-2.9)$ & $0.7(0.1-3.4)$ \\
\hline \multicolumn{5}{|l|}{ Duration of stay (months) } \\
\hline $1-6$ & $12(26.1)$ & $23(46.0)$ & 1.0 (reference) & 1.0 (reference) \\
\hline $6-12$ & $11(23.9)$ & $10(20.0)$ & $2.1(0.7-6.4)$ & $1.3(0.2-7.1)$ \\
\hline$\geq 12$ & $23(50.0)$ & $17(34.0)$ & $2.6(1.0-6.6)$ & $2.0(0.6-6.5)$ \\
\hline \multicolumn{5}{|l|}{ Level of intellectual functioning } \\
\hline Borderline intellectual functioning & $18(39.1)$ & $26(52.0)$ & 1.0 (reference) & 1.0 (reference) \\
\hline Mild/moderate intellectual dis. & $28(60.9)$ & $24(48.0)$ & $1.7(0.7-3.8)$ & $1.5(0.4-4.9)$ \\
\hline \multicolumn{5}{|l|}{ Psychiatric diagnosis } \\
\hline Psychotic disorder & $17(37.0)$ & $5(10.0)$ & $5.3(1.8-15.9)$ & $13.2(2.3-74.8)$ \\
\hline Personality disorder & $9(19.6)$ & $11(22.0)$ & $1.0(0.4-2.6)$ & $2.4(0.5-10.8)$ \\
\hline Substance related disorder & $5(10.9)$ & $4(8.0)$ & $1.4(0.4-5.6)$ & $2.4(0.3-18.6)$ \\
\hline Impulse control disorder** & $10(21.7)$ & $17(34.0)$ & $0.5(0.2-1.2)$ & $1.3(0.3-6.1)$ \\
\hline \multicolumn{5}{|l|}{ Behavioral diagnosis } \\
\hline Antisocial behavior & 9 (19.6) & $16(32.0)$ & $0.5(0.2-1.3)$ & $0.7(0.1-3.2)$ \\
\hline Aggressive behavior & $33(71.7)$ & $26(52.0)$ & $2.3(1.0-5.5)$ & $7.1(1.9-27.4)$ \\
\hline Withdrawal behavior & $7(15.2)$ & $6(12.0)$ & $1.3(0.4-4.3)$ & $2.8(0.4-18.8)$ \\
\hline Sexually unacceptable behavior & $6(13.0)$ & $9(18.0)$ & $0.7(0.2-2.1)$ & $1.7(0.3-8.2)$ \\
\hline Bizarre behavior & $9(19.6)$ & $2(4.0)$ & $5.8(1.2-28.7)$ & $15.3(1.7-137.7)$ \\
\hline Attention seeking behavior & $12(26.1)$ & $8(16.0)$ & $1.9(0.7-5.0)$ & $4.4(0.9-21.1)$ \\
\hline
\end{tabular}

* Multiple drug use (regular and/or as needed: 1) two antipsychotics; 2) antipsychotic \& anticonvulsant; 3) antidepressant \& anticonvulsant; 4) antidepressant \& antipsychotic; 5) tranquilizer \& benzodiazepine \& antipsychotic; 6) tranquilizer \& benzodiazepine \& anticonvulsant; and 7) tranquilizer \& benzodiazepine \& antidepressant.

** Included are: attention deficit- and disruptive behavior disorders and impulse control disorders not elsewhere classified. 
Table 3

Involuntary measures - in percentages of days foregoing multiple drug use-and multiple drug use* after the first week of admission-Odds ratios calculated with $95 \%$ confidence interval $(95 \% \mathrm{CI})$.

\begin{tabular}{ccll}
\hline & $\begin{array}{l}\text { Multiple } \\
\text { drug users } \\
(\mathrm{n}=27) \\
\mathrm{n}(\%)\end{array}$ & $\begin{array}{l}\text { No multiple } \\
\text { drug users } \\
(\mathrm{n}=50)\end{array}$ & $\begin{array}{l}\text { Odds ratio } \\
(95 \% \mathrm{CI})\end{array}$ \\
\hline $\begin{array}{l}\mathrm{n}(\%) \\
\text { Involuntary measures }\end{array}$ & & & \\
No measures & $18(66.7)$ & $41(82.0)$ & 1.0 (reference) \\
Measures $<10 \%$ & $3(11.1)$ & $5(10.0)$ & $0.7(0.2-3.2)$ \\
Measures $>10 \%$ & $6(22.2)$ & $4(8.0)$ & $2.3(0.7-8.4)$ \\
\hline
\end{tabular}

* Multiple drug use (regular and/or as needed): 1) two antipsychotics; 2) antipsychotic \& anticonvulsant; 3) antidepressant \& anticonvulsant; 4) antidepressant \& antipsychotic; 5) tranquilizer \& benzodiazepine \& antipsychotic; 6) tranquilizer \& benzodiazepine \& anticonvulsant; and 7) tranquilizer \& benzodiazepine \& antidepressant.

using multiple drugs after the first week of admission [27] were entered into this analysis. Involuntary measures were associated with multiple drug use with an odds ratio of 2.3 (95\% confidence interval: 0.7-8.4) (Table 3).

\section{Discussion}

In the present study, we found that during their hospital stay approximately $80 \%$ of the patients used one or more psychotropics including anticonvulsants with highest use of antipsychotics, prescribed to $66.7 \%$. The use of psychotropics was high compared to other studies among people with intellectual disabilities in institutions in which prevalence rates from 44 to $60 \%$ were found [13]. When anticonvulsants were excluded only slightly lower prevalence rates were found. High prevalence rates are not surprising because prerequisites for admission on our ward are psychiatric and behavioral disorders. The relative high use of antipsychotics is in agreement with other studies although different prevalence rates for different samples of people were found [14-17].

Multiple drug use was associated with aggressive behavior. There was also an association with attention seeking behavior and involuntary measures, although not significant possibly due to small numbers. Many patients admitted to the ward have long histories of recurrent admissions to psychiatric hospitals and to specialized units of residential settings and it is likely that our findings indicate difficulties in the management of patients with socially disruptive behavior. This is underlined by the finding that psychotropic drugs were used in high dosages and the tendency to prescribe multiple drugs in patients with a duration of stay of more than a year. The association between psychotic disorder and multiple medication was not surprising because this disorder is often accompanied with agitation. Therefore, combinations of antipsychotics with benzodiazepines and tranquilizers are frequently used. Another explanation for the association between psychotic disorder and multiple drug use is the fact that among patients with learning disabilities and aggressive behavior sometimes an underlying psychotic disorder is suspected whereas with a formal psychiatric evaluation no psychotic symptoms are observed. The complex treatment of patients with socially disruptive behavior is emphasized by the results of other studies among people with learning disabilities in which an association between such behavior and the use of antipsychotic drugs was found $[9,18,19]$. The association between bizarre behavior and multiple drug use may be explained by the fact that it is difficult to interpret this behavior and that it may be related to severe disorders such as autistic disorder and psychotic disorder for which a broad spectrum of psychotropics are prescribed. We did not consider the combined use of antipsychotics with anticholinergics as multiple psychotropic drug use as this combination is commonly used because of extrapyramidal side effects. Nevertheless, it is possible that many patients who were maintained on longterm antipsychotics, actually no longer require these agents, which may be a source of cognitive side-effects or elevated mood in sensitive patients [20]. We found that four of nine multiple drug users who used anticonvulsants had no seizure disorder. Anticonvulsants are often used for psychiatric and behavioral purposes [21].

In this study, no effect of gender, age and level of intellectual functioning on multiple psychotropic drug use was found. The lack of a gender effect is consistent with most studies looking at this variable $[8,13,16]$. Concerning age and psychotropic use, some researchers found no relation whereas others have found that older people use more psychotropics $[8,13,16]$. Jacobson found that young and middle aged adults received higher rates of psychotropic medication than children, adolescents and older people [22]. Inconsistent results are reported concerning the association of level of intellectual functioning and psychotropic drug use $[8,13,16]$.

In conclusion, we found a prevalence of multiple psychotropic drug use of $48 \%$ in this population. A clear association between multiple drugs and socially disruptive behavior was found indicating that difficulties in the management of this behavior is a common problem. More detailed investigations into the rational of prescribing multiple drugs in settings for people with intellectual disabilities are needed.

\section{References}

[1] Borthwick-Duffy SA. Epidemiology, and prevalence of psychopathology in people with mental retardation. J Consult Clin Psychol 1994;62:17-27.

[2] Campbell M, Malone P. Mental retardation, and psychiatric disorders. Hosp Community Psychiatry 1991;42:374-9.

[3] Reiss S. Introduction. In: Handbook of challenging behavior: mental health aspects of mental retardation. Worthington, Ohio, IDS Publishing Corporation, 1994. p. 1-40. 
[4] Rojahn J, Tassé MJ. Psychopathology in mental retardation. In: Jacobson JW, Mulick JA, editors. Manual of diagnosis and professional practice in mental retardation. Washington DC, American Psychological Association, 1996. p. 147-56.

[5] Szymanski LS. Mental retardation, and mental health. Concepts, aetiology, and incidence. In: Bouras $\mathrm{N}$ editor. Mental health in mental retardation. Recent advances and practices. Cambridge, England, Cambridge University Press, 1994. p. 19-33.

[6] Coughlan BJ. Psychopharmacology in the treatment of people with learning disabilities: a review. Ment Health Learn Disabil Care 2000; 3:304-7.

[7] Sommi RW, Benefield WH, Curtis JL, et al. Drug interactions with psychotropic medications. In: Aman MG, Reiss S, editors. Psychotropic medications and developmental disabilities. The International consensus handbook. Columbus, OH, Ohio State University, 1998. p. 115-32.

[8] Aman MG, Sarphare G, Burrow WH. Psychotropic drugs in group homes: prevalence, and relation to demographic/psychiatric variables. Am J Ment Retard 1995;99:500-9.

[9] Kiernan C, Reeves D, Alborz A. The use of antipsychotic drugs with adults with learning disabilities, and challenging behaviour. J Intellect Disabil Res 1995;39:263-74.

[10] Gardner Wilson J, Lott RS, Tsai L. Side effects: recognition, and management. In: Aman MG, Reiss S, editors. Psychotropic medications and developmental disabilities. The International consensus handbook.Columbus, OH, Ohio State University, 1998. p. 95-114.

[11] Tuinier S, Verhoeven WMA. Pharmacological advances in mental retardation: a need for reconceptualization. Curr Opin Psychiatry 1994;7:380-6.

[12] Anonymous. ATC classification index with DDDs: January 2001. Oslo, WHO collaborating Centre for Drug Statistics, and Methodology, 2001.
[13] Singh NN, Ellis CR, Wechsler H. Psychopharmacoepidemiology of mental retardation. 1966 to 1995. J Child Adolesc Psychopharmacol 1997;7:255-67.

[14] Intagliata J, Rinck C. Psychoactive drug use in public, and community residential facilities for mentally retarded persons. Psychopharmacol Bull 1985;21:268-78.

[15] Meins W, Auwetter J, Krausz M, Turnier Y. Treatment with psychotropic drugs in various facilities for mentally handicapped patients. Nervenarzt 1993;64:451-5.

[16] Rinck C. Epidemiology, and psychoactive medication. In: Aman MG, Reiss S editors. Psychotropic medications and developmental disabilities. The International consensus handbook. Columbus, OH, Ohio State University, 1998. p. 31-44.

[17] Spreat S, Conroy JW, Jones JC. Use of psychotropic medication in Oklahoma: a statewide survey. Am J Ment Retard 1997;102:80-5.

[18] Branford D, Collacott RA, Thorp C. The prescribing for people with learning disabilities living in Leicestershire. J Intellect Disabil Res 1995;39:495-500.

[19] Stone RK, Alvarez WF, Ellman G, Hom AC, White JF. Prevalence, and prediction of psychotropic drug use in California developmental centers. Am J Ment Retard 1989;93:627-32.

[20] Stanilla JK, Simpson GM. Treatment of extrapyramidal side effects. In: Schatzberg AF, Nemeroff CB, editors. The American psychiatric press textbook of psychopharmacology. $2^{\text {nd }}$ edition. Washington, DC, London, American Psychiatric Press, Inc, 1998. p. 349-75.

[21] Pointdexter AR, Cain N, Clarke DJ, et al. Mood stabilizers. In: Aman MG, Reiss S, editors. Psychotropic medications and developmental disabilities. The International consensus handbook. Columbus, $\mathrm{OH}$, Ohio State University, 1998. p. 215-27.

[22] Jacobson JW. Problem behavior, and psychiatric impairment within a developmentally disabled population III: psychotropic medication Res Dev Disabil 1988;9:23-38. 